\title{
A New Method for In Vivo Analysis of the Performances of a Heat and Moisture Exchanger (HME) in Mechanically Ventilated Patients
}

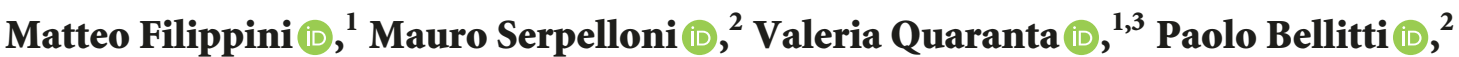 \\ Emilio Sardini $(\odot)^{2}$ and Nicola Latronico ${ }^{1,3}$ \\ ${ }^{1}$ Department of Anaesthesia and Critical Care Medicine, University of Brescia at Spedali Civili di Brescia, 25100 Brescia, Italy \\ ${ }^{2}$ Department of Information Engineering, University of Brescia, 25123 Brescia, Italy \\ ${ }^{3}$ Department of Medical and Surgical Specialties, Radiological Sciences and Public Health, Italy
}

Correspondence should be addressed to Matteo Filippini; matteo.filippinil23@gmail.com

Received 30 August 2018; Revised 26 January 2019; Accepted 3 February 2019; Published 26 February 2019

Academic Editor: Kazuyoshi Kuwano

Copyright (c) 2019 Matteo Filippini et al. This is an open access article distributed under the Creative Commons Attribution License, which permits unrestricted use, distribution, and reproduction in any medium, provided the original work is properly cited.

\begin{abstract}
Aim. To evaluate the conditioning capabilities of the $\mathrm{DAR}^{\mathrm{TM}}$ Hygrobac $^{\mathrm{TM}} \mathrm{S}$, a Heat and Moisture Exchanger (HME), using a new device to measure the temperature $(\mathrm{T})$ and the absolute humidity $(\mathrm{AH})$ of the ventilated gases in vivo during mechanical ventilation in Intensive Care Unit (ICU) patients. Materials and Methods. In 49 mechanically ventilated ICU patients, we evaluated T and AH, indicating the HME efficacy, during the inspiratory phase upstream and downstream the HME and the ratio of inspired AH to expired $\mathrm{AH}$ and the difference between expired $\mathrm{T}$ and inspired $\mathrm{T}$ indicated the HME efficiency. Efficacy and efficiency were assessed at three time points: at baseline ( $\mathrm{t}_{0}$, HME positioning time), at 12 hours $\left(\mathrm{t}_{1}\right)$, and at 24 hours $\left(\mathrm{t}_{2}\right)$ using a dedicated, ad hoc built wireless device. Differences over time were evaluated using one-way ANOVA for repeated measures, whereas differences between in vivo and laboratory values (declared by the manufacturer according to UNI ${ }^{\circledR}$ EN ISO 9360 international standard) were evaluated using one-sample Student t-test. Results. 49 HMEs were analysed in vivo during mechanical ventilation. T and AH means (SD) of the inspired gas (the efficacy) were $31.5^{\circ} \mathrm{C}(1.54)$ and $32.3 \mathrm{mg} / \mathrm{l}(2.60)$ at $\mathrm{t}_{0}, 31.1^{\circ} \mathrm{C}(1.34)$ and $31.7 \mathrm{mg} / \mathrm{l}(2.26)$ at $\mathrm{t}_{1}$, and $31^{\circ} \mathrm{C}(1.29)$ and $31.4 \mathrm{mg} / \mathrm{l}(2.27)$ at $\mathrm{t}_{2}$. Both efficiency parameters were constant over time (inspired AH/expired $\mathrm{AH}=89 \%$, $\mathrm{p}=0.24$; and expired $\mathrm{T}$-inspired $\mathrm{T}=2.2^{\circ} \mathrm{C}, \mathrm{p}=0.81$ ). Compared with laboratory values, in vivo $\mathrm{T}$ and $\mathrm{AH}$ indicating efficacy were significantly lower $(p<0.01)$, whereas the efficiency was significantly higher $(p<0.01)$. Conclusions. HME performances can be accurately assessed for prolonged periods in vivo during routine mechanical ventilation in ICU patients. Temperature and absolute humidity of ventilated gases in vivo were maintained within the expected range and remained stable over time. HME efficacy and efficiency in vivo significantly differed from laboratory values.
\end{abstract}

\section{Introduction}

Conditioning (heating and humidifying) of inspired gases is one of the functions of the upper airways. In critically ill patients, tracheal intubation or tracheostomy limits the efficacy of this process; therefore, when gases reach the lower airways, they are inadequately humidified and heated. This inadequate humidification may lead to respiratory heat loss, airway obstruction due to thick secretions, and impairment of the mucociliary function. Heat and Moisture Exchangers (HMEs) combined with microbiological filters are currently recommended to reduce the risk of respiratory complications caused by inadequate warming and humidification of the gases delivered to mechanically ventilated patients [1-9].

The performance of HMEs is dependent upon the type of device, the ventilator setting (i.e., minute ventilation, and tidal volume), and room and patient temperatures. Based on normal physiology, HMEs should be able to provide 30 to $33 \mathrm{mg} / \mathrm{l}$ of water to the airways at $30-36^{\circ} \mathrm{C}$ for optimal use in the Intensive Care Unit (ICU) $[10,11]$. The commercially available devices are tested in the laboratory according to $\mathrm{UNI}^{\circledR}$ EN ISO 9360 international standard because the in vivo measurements (during mechanical ventilation) of the 
humidity and temperature are technically demanding [1216]. Recently, some in vivo methods have been developed; such methods enable the measurement of water exchange performance of a variety of HMEs within a short timeframe $[17,18]$.

In this study, we applied a new method for a rapid and noninvasive assessment of the HME performance during mechanical ventilation. The main characteristic of this method was the use of a new device which can also be applied for long-term assessment of the HME performance. We measured the conditioning capabilities of a commercially available HME and its performance variations over time during a 24-hour period of mechanical ventilation with continuous HME use in a widely heterogeneous population of artificially ventilated ICU patients.

\section{Materials and Methods}

This was a retrospective analysis of prospectively collected data from November 2016 to August 2017 at the general ICU of the Spedali Civili, a regional hospital, affiliated with the University of Brescia, Italy. We enrolled 49 critically ill patients who had been mechanically ventilated for at least 24 hours with use of a HME to provide adequate passive gas conditioning. These patients were studied with a new device, built by researchers of the Department of Information Engineering of the University of Brescia (MS, PB, and ES) to measure the performances of the $\mathrm{DAR}^{\mathrm{TM}} \mathrm{Hygrobac}^{\mathrm{TM}} \mathrm{S}, \mathrm{a}$ HME of standard clinical use at the time of the study.

The study was approved by the Ethics Committee of the University of Brescia at Spedali Civili (protocol number 2440, June 20th, 2016) that waived the requirement for consent because the study only involved recording data from the medical device with complete patients anonymisation (i.e., the data subjects were not identifiable).

The HMEs were changed routinely every 24 hours as per manufacturer's recommendations or earlier in case of copious secretions or when increases in airway pressure were thought to be due to increased HME resistance. The ventilator circuit remained intact for the duration of the period of ventilation. The ventilatory settings were not modified during the 24hour study period (unless required by clinical conditions, but never significantly). The incharge intensivist was not directly involved in the study and took full responsibility for clinical and ventilatory management.

2.1. Description of the Experiment and Definitions. In this study, we defined the following HME performance indicators:

(i) Input: as the temperature ( $\mathrm{T}$ ) and absolute humidity $(\mathrm{AH})$ of fresh gases flowing from the ventilator to the HME during inspiration;

(ii) Load: as the $\mathrm{T}$ and $\mathrm{AH}$ of the gases flowing from the patient to the HME during expiration;

(iii) Return: as the $\mathrm{T}$ and $\mathrm{AH}$ of gases flowing from the HME to the patient during inspiration (it describes the "efficacy"); (iv) Loss: as the T and AH of gases leaving the HME for the ventilator during expiration;

(v) Yield: as the AH return to AH load ratio (it describes the "efficiency");

(vi) Thermal differential: as the difference between $\mathrm{T}$ load and T return (it describes the "efficiency");

$\mathrm{T}$ and $\mathrm{AH}$ values were measured by means of the sensors described below.

Data were recorded in three different moments:

(i) at HME positioning time $\left[\mathbf{t}_{\mathbf{0}}\right]$

(ii) after 12 hours of use [ $\left.\mathbf{t}_{\mathbf{1}}\right]$

(iii) at the end of 24 hours of use [ $\left.\mathbf{t}_{2}\right]$

Tidal volumes, respiratory rates, minute ventilation, inspiration:expiration time (I:E) ratios, and room and patient temperatures were also recorded in those moments.

We assessed the following: (a) the absolute $\mathrm{T}$ and $\mathrm{AH}$ values of input, load, return, loss, yield, and thermal differential; (b) their variation over time (24 hours); and (c) the differences between in vivo obtained values of HME performance indicators and their laboratory values declared by the manufacturer in the technical sheet and/or prescribed by the UNI ${ }^{\circledR}$ EN ISO 9360 international standard. In particular, T and $\mathrm{AH}$ declared laboratory values (efficacy) were $32.3^{\circ} \mathrm{C}$ and $33.6 \mathrm{mg} / \mathrm{l}$, respectively, whereas efficiency laboratory values (inspired $\mathrm{AH} /$ expired $\mathrm{AH}$ and expired-inspired $\mathrm{T}$ ) were $77 \%$ and $4.7^{\circ} \mathrm{C}$, respectively.

2.2. Description of the Instrument. The measurement system was composed of two main sections, called Measuring Section and Reading Section. The first was the core of the project and it executed the main operations: reading the sensors, building the data block, and managing the Bluetooth ${ }^{\circledR}$ Low Energy (BLE) connection; this was also subdivided into two parts: machine side and patient side.

Project specifications required two different measurement points, upstream and downstream the HME filter. Upstream the HME (machine side), $\mathrm{T}$ and relative humidity $(\mathrm{RH})$ were measured using the IST ${ }^{\circledR}$ HYT 271 sensor (Figure 1) and downstream that (patient side) only $\mathrm{T}$ using the RTD HERAEUS ${ }^{\circledR}$ M222 Pt1000 sensor (Figure 2), considering that on the patient's side the air is always almost saturated in water content (RH 100\%) during expiration and it is about RH 98\% during inspiration [21, 22]. The Reading Section read the data sent by Measuring Section and converted the raw data to $\mathrm{T}$ and $\mathrm{AH}$ values by adopting the formulas reported elsewhere [19] (Figure 3).

The complete system, measuring module (sensors and electronics) and display module, was validated in the laboratory before clinical trials. After an evaluation in the climatic chamber, a specific analysis of the dynamic behaviour of the humidity and temperature sensors has been performed, including a comparison of the measured data to typical clinical $\mathrm{T}$ and $\mathrm{AH}$ variation to assess error in the evaluation of $\mathrm{T}$ and $\mathrm{AH}$ values. The results showed that the percentage error of the measured values compared to the real signals was 
TABLE 1: Ventilatory variables at $t_{0}, t_{1}$, and $t_{2}$ assessment time; SD: standard deviation.

\begin{tabular}{|c|c|c|c|c|}
\hline & $\begin{array}{c}\mathrm{t}_{0}: \text { mean } \\
(\mathrm{SD})\end{array}$ & $\begin{array}{c}\mathrm{t}_{1}: \text { mean } \\
(\mathrm{SD})\end{array}$ & $\begin{array}{c}\mathrm{t}_{2}: \text { mean } \\
(\mathrm{SD})\end{array}$ & Differences over time $(\mathrm{p})$ \\
\hline \multirow{2}{*}{ Tidal volume (ml) } & 443 & 431 & 425 & \multirow{2}{*}{0.70} \\
\hline & $(136)$ & $(109)$ & $(93)$ & \\
\hline \multirow{2}{*}{ Respiratory rate $\left(\mathrm{min}^{-1}\right)$} & 18 & 18 & 18 & \multirow{2}{*}{0.82} \\
\hline & $(6.55)$ & $(6.91)$ & $(6.91)$ & \\
\hline \multirow{2}{*}{ Minute ventilation $(1 / \mathrm{min})$} & 7.46 & 7.52 & 7.42 & \multirow{2}{*}{0.92} \\
\hline & $(2.49)$ & $(2.13)$ & $(2.41)$ & \\
\hline \multirow{2}{*}{$\mathrm{I}: \mathrm{E}$ ratio } & 0.53 & 0.59 & 0.58 & \multirow{2}{*}{0.70} \\
\hline & $(0.26)$ & $(0.27)$ & $(0.28)$ & \\
\hline \multirow{2}{*}{ Room temperature $\left({ }^{\circ} \mathrm{C}\right)$} & 24.0 & 23.3 & 23.7 & \multirow{2}{*}{0.09} \\
\hline & $(1.75)$ & $(1.14)$ & $(1.16)$ & \\
\hline \multirow{2}{*}{ Patient temperature $\left({ }^{\circ} \mathrm{C}\right)$} & 36.7 & 36.9 & 36.7 & \multirow{2}{*}{0.76} \\
\hline & $(0.70)$ & $(0.75)$ & $(0.59)$ & \\
\hline
\end{tabular}

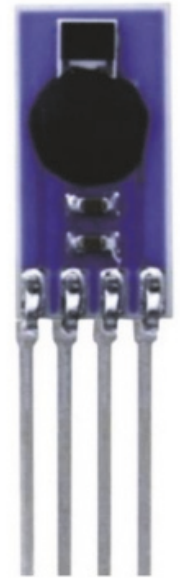

FIgURE 1: T and AH sensor: IST ${ }^{\circledR}$ HYT 271 (machine side).

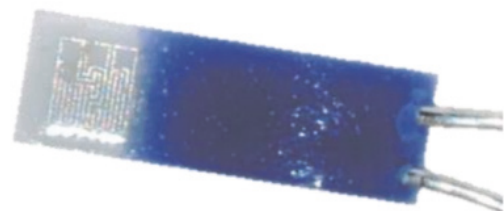

FIgUre 2: Tsensor: RTD HERAEUS ${ }^{\circledR}$ M222 Pt1000 (patient side).

from $5 \%$ to $14 \%$ depending on respiratory frequency rate and I:E ratio, so the error trend was linear with the increase of the respiratory frequency rate and was inversely proportional to the I:E ratio [23-30].

2.3. Data Presentation and Statistical Analysis. All variables were expressed as means and standard deviations (SD).
We estimated that a sample of $36 \mathrm{HMEs}$ would provide $80 \%$ power to detect a difference of $2^{\circ} \mathrm{C}$ in $\mathrm{T}, 2 \mathrm{mg} / \mathrm{l}$ of $\mathrm{AH}$, and a $5 \%$ variation in the yield, at a two-sided alpha level of 0.05 .

Variations over time of the HME performance indicators (input, load, return, loss, yield, and thermal differential) were analysed using ANOVA for repeated measures. The differences between in vivo observed and manufacturerdeclared laboratory values were analysed using one-sample Student t-test. A p $<0.05$ was considered as statistically significant.

\section{Results}

We evaluated 49 HMEs in vivo in 49 mechanically ventilated ICU patients. For 36 HMEs, the performances were analysed for 24 hours according to the study protocol, while for 13 HMEs the assessment was interrupted after 12 hours because of device replacement for clinical needs.

Table 1 describes the ventilatory variables, as well as room and patient temperatures at $t_{0}, t_{1}$, and $t_{2}$. The minute ventilation varied between 7.42 and $7.52 \mathrm{l} / \mathrm{min}$, room temperature between 23 to $24^{\circ} \mathrm{C}$, and patient temperature between 36.7 and $36.9^{\circ} \mathrm{C}$. There were no statistically significant changes in these parameters over time.

Concerning the main aims of the study, (a) $\mathrm{T}$ and $\mathrm{AH}$ of the inspired gases, describing the efficacy, are shown in Table 2, (b) none of the measured parameters significantly varied over time (Table 2, last column), and (c) differences between in vivo observed and laboratory values are shown in Table 3.

In vivo measured efficacy was lower than the laboratory values for both $\mathrm{T}$ and $\mathrm{AH}$, whereas the efficiency was higher in vivo than in laboratory conditions $(\mathrm{p}<0.01)$. Moreover, our clinical setting was significantly different in terms of tidal volumes, respiratory rates, minute ventilations, I:E ratios, room temperatures, patient temperatures, and load $\mathrm{T}$ and $\mathrm{AH}$, compared to the laboratory setting (Table 3 ). 
TABLE 2: Temperature (T) and absolute humidity (AH) values of Heat and Moisture Exchanger (HME) performance indicators; SD: standard deviation.

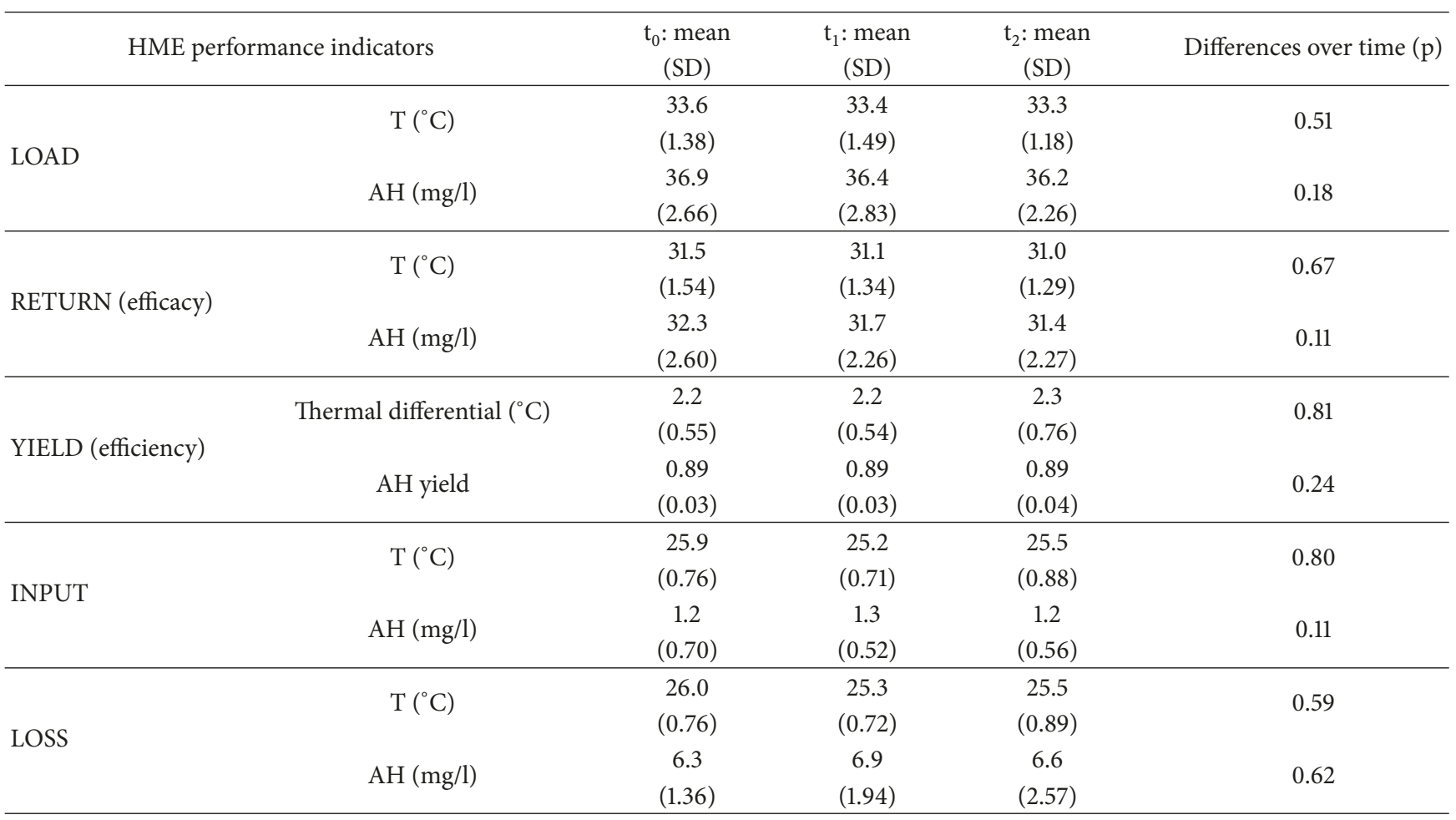

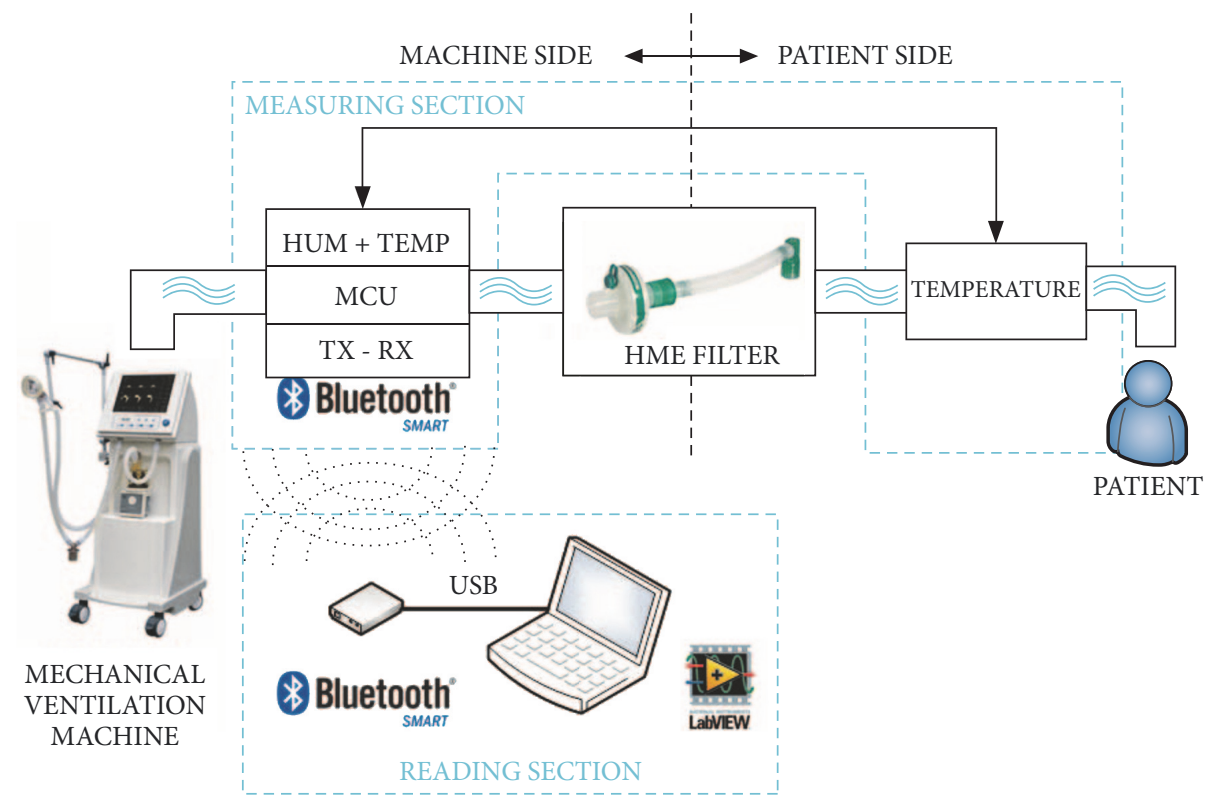

FIgURE 3: Data acquisition system.

\section{Discussion}

In this retrospective study, we analysed the $\mathrm{DAR}^{\mathrm{TM}}$ Hygrobac $^{\mathrm{TM}} \mathrm{S}$ HME performances in vivo during routine mechanical ventilation in critically ill patients by applying a newly devised wireless, portable device of reduced weight, with a user-friendly interface and long battery life, measuring the gas temperature and absolute humidity with low invasiveness for the patients and complete integration with respiratory circuit. By using a complete list of HME performance indicators, we found that the in vivo efficacy of the HME was within the required range for optimal gas conditioning which should be maintained between 30 and $36^{\circ} \mathrm{C}$ of $\mathrm{T}$ and 30 and $33 \mathrm{mg} / \mathrm{l}$ of $\mathrm{AH}$ and did not significantly 
TABLE 3: Comparison of temperature (T) and absolute humidity (AH) of Heat and Moisture Exchanger (HME) performance indicators between laboratory values as declared by the manufacturer and in vivo measured values. All values are expressed as laboratory values minus in vivo values and were measured at a tidal volume of $500 \mathrm{ml}$.

\begin{tabular}{|c|c|c|c|c|}
\hline $\begin{array}{l}\text { HME performance indicators } \\
\text { and ventilatory parameters }\end{array}$ & Laboratory - in vivo $\mathrm{t}_{0}$ & Laboratory - in vivo $\mathrm{t}_{1}$ & Laboratory - in vivo $t_{2}$ & $\begin{array}{c}\text { Laboratory values } \\
{[15,16,19,20]}\end{array}$ \\
\hline Load $\mathrm{T}\left({ }^{\circ} \mathrm{C}\right)$ & $\begin{array}{c}+3.4 \\
(\mathrm{p}<0.01)\end{array}$ & $\begin{array}{c}+3.7 \\
(\mathrm{p}<0.01)\end{array}$ & $\begin{array}{c}+3.7 \\
(\mathrm{p}<0.01)\end{array}$ & 37.0 \\
\hline Load AH (mg/l) & $\begin{array}{c}+6.9 \\
(\mathrm{p}<0.01)\end{array}$ & $\begin{array}{c}+7.4 \\
(\mathrm{p}<0.01)\end{array}$ & $\begin{array}{c}+7.6 \\
(\mathrm{p}<0.01)\end{array}$ & 43.8 \\
\hline Return T (efficacy) $\left({ }^{\circ} \mathrm{C}\right)$ & $\begin{array}{c}+0.8 \\
(\mathrm{p}<0.01)\end{array}$ & $\begin{array}{c}+1.2 \\
(\mathrm{p}<0.01)\end{array}$ & $\begin{array}{c}+1.3 \\
(\mathrm{p}<0.01)\end{array}$ & 32.3 \\
\hline Return AH (efficacy) (mg/l) & $\begin{array}{c}+1.3 \\
(\mathrm{p}<0.01)\end{array}$ & $\begin{array}{c}+2.0 \\
(\mathrm{p}<0.01)\end{array}$ & $\begin{array}{c}+2.2 \\
(\mathrm{p}<0.01)\end{array}$ & 33.6 \\
\hline $\begin{array}{l}\text { Thermal differential (efficiency) } \\
\left({ }^{\circ} \mathrm{C}\right)\end{array}$ & $\begin{array}{c}+2.5 \\
(\mathrm{p}<0.01)\end{array}$ & $\begin{array}{c}+2.5 \\
(\mathrm{p}<0.01)\end{array}$ & $\begin{array}{c}+2.4 \\
(\mathrm{p}<0.01) \\
\end{array}$ & 4.7 \\
\hline AH yield (efficiency) & $\begin{array}{c}-0.12 \\
(\mathrm{p}<0.01)\end{array}$ & $\begin{array}{c}-0.12 \\
(\mathrm{p}<0.01)\end{array}$ & $\begin{array}{c}-0.12 \\
(\mathrm{p}<0.01)\end{array}$ & 0.77 \\
\hline Input $\mathrm{T}\left({ }^{\circ} \mathrm{C}\right)$ & $\begin{array}{c}-2.9 \\
(\mathrm{p}<0.01)\end{array}$ & $\begin{array}{c}-2.2 \\
(\mathrm{p}<0.01)\end{array}$ & $\begin{array}{c}-2.5 \\
(\mathrm{p}<0.01)\end{array}$ & 23.0 \\
\hline Input AH (mg/l) & $\begin{array}{c}-0.2 \\
(p=0.03)\end{array}$ & $\begin{array}{c}-0.3 \\
(p<0.01)\end{array}$ & $\begin{array}{c}-0.2 \\
(p=0.049)\end{array}$ & 1.0 \\
\hline Loss $\mathrm{T}\left({ }^{\circ} \mathrm{C}\right)$ & $\begin{array}{c}-3.0 \\
(\mathrm{p}<0.01)\end{array}$ & $\begin{array}{c}-2.3 \\
(\mathrm{p}<0.01)\end{array}$ & $\begin{array}{c}-2.5 \\
(\mathrm{p}<0.01)\end{array}$ & 23.0 \\
\hline Loss AH (mg/l) & $\begin{array}{c}-0.3 \\
(\mathrm{p}=0.10)\end{array}$ & $\begin{array}{c}-0.9 \\
(p<0.01)\end{array}$ & $\begin{array}{c}-0.6 \\
(p=0.16)\end{array}$ & 6.0 \\
\hline Tidal volume (ml) & $\begin{array}{c}+57 \\
(p<0.01)\end{array}$ & $\begin{array}{c}+69 \\
(p<0.01)\end{array}$ & $\begin{array}{c}+75 \\
(\mathrm{p}<0.01)\end{array}$ & 500 \\
\hline Respiratory rate $\left(\mathrm{min}^{-1}\right)$ & $\begin{array}{c}-3 \\
(\mathrm{p}<0.01) \\
\end{array}$ & $\begin{array}{c}-3 \\
(\mathrm{p}<0.01)\end{array}$ & $\begin{array}{c}-3 \\
(\mathrm{p}<0.01)\end{array}$ & 15 \\
\hline Minute ventilation $(1 / \mathrm{min})$ & $\begin{array}{c}+0.04 \\
(\mathrm{p}=0.91)\end{array}$ & $\begin{array}{c}-0.02 \\
(p=0.96)\end{array}$ & $\begin{array}{c}+0.08 \\
(p=0.84)\end{array}$ & 7.5 \\
\hline I:E ratio & $\begin{array}{c}+0.47 \\
(\mathrm{p}<0.01) \\
\end{array}$ & $\begin{array}{c}+0.41 \\
(\mathrm{p}<0.01)\end{array}$ & $\begin{array}{c}+0.42 \\
(\mathrm{p}<0.01)\end{array}$ & 1 \\
\hline Room temperature $\left({ }^{\circ} \mathrm{C}\right)$ & $\begin{array}{c}-1.0 \\
(p<0.01)\end{array}$ & $\begin{array}{c}-0.3 \\
(p=0.63)\end{array}$ & $\begin{array}{c}-0.7 \\
(p<0.01)\end{array}$ & 23.0 \\
\hline Patient temperature $\left({ }^{\circ} \mathrm{C}\right)$ & $\begin{array}{c}+0.4 \\
(\mathrm{p}<0.01)\end{array}$ & $\begin{array}{c}+0.1 \\
(\mathrm{p}=0.12)\end{array}$ & $\begin{array}{c}+0.3 \\
(\mathrm{p}<0.01)\end{array}$ & 37.0 \\
\hline
\end{tabular}

change over time. The HME in vivo efficacy was lower than expected based on laboratory values; i.e., the HME provided less heat and humidity than anticipated; on the contrary, the efficiency was higher; i.e., the ratio of $\mathrm{AH}$ return to load was $89 \%$, which was significantly higher than the $77 \%$ expected value based on laboratory values. The reasons for differences in efficacy and efficiency between in vivo and laboratory values are speculative. Other factors, in addition to the HME itself, may have influenced these parameters. The patient's and room temperature, the type and the length of the tracheal tube, and the ventilatory setting might have played a role; however, the evidence supporting this hypothesis has not been evaluated in other studies. Importantly, these ambient factors are an integral part of in vivo functioning of the HME and should be assessed in future studies aiming at quantifying their impact on HME performances.

\section{Conclusions}

In conclusion, we demonstrated that HME performances can be accurately assessed for prolonged periods in vivo during routine mechanical ventilation in ICU patients with the use of a newly introduced device. Temperature and absolute humidity of ventilated gases in vivo were maintained within the expected range and remained stable over the entire observation period. However, HME efficacy and efficiency in vivo differed significantly from laboratory values. 


\section{Data Availability}

All the data used to support the findings of this study are available from the corresponding author upon request.

\section{Conflicts of Interest}

The authors declare that there are no conflicts of interest regarding the publication of this paper.

\section{Acknowledgments}

The authors heartily thank Dr. Elena Raffetti, MD, Ph.D. candidate, for her suggestions, which improved the quality of this work. This research was funded with internal funds from the University of Brescia, Italy.

\section{References}

[1] J. Chalon, D. A. Loew, and J. Malebranche, "Effects of dry anesthetic gases on tracheobronchial ciliated epithelium," Anesthesiology, vol. 37, no. 3, pp. 338-343, 1972.

[2] J. D. K. Burton, "Effects of dry anaesthetic gases on the respiratory mucous membrane," The Lancet, vol. 1, no. 7223, pp. 235-238, 1962.

[3] A. R. Forbes, "Temperature, humidity and mucus flow in the intubated trachea," British Journal of Anaesthesia, vol. 46, no. 1, pp. 29-34, 1974.

[4] T. Tsuda, H. Noguchi, Y. Takumi, and O. Aochi, "Optimum humidification of air administered to a tracheostomy in dogs. Scanning electron microscopy and surfactant studies," British Journal of Anaesthesia, vol. 49, no. 10, pp. 965-977, 1977.

[5] J. C. van Oostdam, D. C. Walker, K. Knudson, P. Dirks, R. W. Dahlby, and J. C. Hogg, "Effect of breathing dry air on structure and function of airways," Journal of Applied Physiology, vol. 61, no. 1, pp. 312-317, 1986.

[6] T. Dalhamn and J. Rhodin, "Mucous flow and ciliary activity in the trachea of rats exposed to pulmonary irritant gas," British Journal of Industrial Medicine, vol. 13, no. 2, pp. 110-113, 1956.

[7] G. McNulty and L. Eyre, "Humidification in anaesthesia and critical care," BJA Education, vol. 15, no. 3, pp. 131-135, 2015.

[8] H. S. Al Ashry and A. M. Modrykamien Eyre, "Humidification during mechanical ventilation in the adult patient," BioMed Research International, vol. 2014, Article ID 715434, 12 pages, 2014.

[9] R. D. Restrepo and B. K. Walsh, "Humidification during invasive and noninvasive mechanical ventilation: 2012," Respiratory Care, vol. 57, no. 5, pp. 782-788, 2012.

[10] J. Chalon, C. Patel, M. Ali et al., "Humidity and the anesthetized patient," Anesthesiology, vol. 50, no. 3, pp. 195-198, 1979.

[11] M. P. Shelly, G. M. Lloyd, and G. R. Park, "A review of the mechanisms and methods of humidification of inspired gases," Intensive Care Medicine, vol. 14, no. 1, pp. 1-9, 1988.

[12] A. Gedeon and C. Mebius, "The Hygroscopic Condenser Humidifier a New Device for General Use in Anaesthesia and Intensive Care," Anaesthesia, vol. 34, no. 10, pp. 1043-1047, 1979.

[13] C. Mebius, "A comparative evaluation of disposable humidifiers," Acta Anaesthesiol Scand, vol. 27, no. 5, pp. 403-409, 1983.

[14] M. Ogino, R. Kopotic, and F. L. Mannino, "Moisture-conserving efficiency of condenser humidifiers," Anaesthesia, vol. 40, no. 10, pp. 990-995, 1985.
[15] UNI@ EN ISO 9360-1:2009, "Anaesthetic and repiratory equipment: heat and moisture exchangers (HMEs) for humidifying respired gases in humans," 2009.

[16] M. Chandler, "Measurement of heat and moisture exchanger efficiency," Anaesthesia, vol. 68, no. 9, pp. 953-960, 2013.

[17] J. D. Ricard, P. Markowicz, K. Djedaini, L. Mier, F. Coste, and D. Dreyfuss, "Bedside evaluation of efficient airway humidification during mechanical ventilation of the critically ill," Chest, vol. 115, no. 6, pp. 1646-1652, 1999.

[18] J. J. De Castro, F. Bolfi, L. R. De Carvalho, and J. R. C. Braz, “The temperature and humidity in a low-flow anesthesia workstation with and without a heat and moisture exchanger," Anesthesia \& Analgesia, vol. 113, no. 3, pp. 534-538, 2011.

[19] Vaisala, Humidity Conversion Formulas - Calculation Formulas for Humidity, 2013.

[20] https://www.medtronic.com/content/dam/covidien/library/us/ en/product/ventilator-filters/dar-breathing-filter-hme-sellsheet .pdf.

[21] R. Dèry, J. Pelletier, A. Jacques, M. Clavet, and J. J. Houde, "Humidity in anaesthesiology III. Heat and moisture patterns in the respiratory tract during anaesthesia with the semi-closed system," Canadian Anaesthetists' Society Journal, vol. 14, no. 4, pp. 287-298, 1967.

[22] M. Luchetti, A. Stuani, G. Castelli, and G. Marraro, "Comparison of three different humidification systems during prolonged mechanical ventilation," Minerva Anestesiologica, vol. 64, no. 3, pp. 75-81, 1998.

[23] Innovative Sensor Technology (IST), "HYT 271 Datasheet Digital Humidity and Temperature Module".

[24] A. Tripathy, S. Pramanik, A. Manna et al., "Design and development for capacitive humidity sensor applications of lead-free $\mathrm{Ca}, \mathrm{Mg}, \mathrm{Fe}$, Ti-oxides-based electro-ceramics with improved sensing properties via physisorption," Sensors, vol. 16, no. 7, 2016.

[25] N. David, P. Wild, and N. Djilali, "Parametric study of a polymer-coated fibre-optic humidity sensor," Measurement Science and Technology, vol. 23, no. 3, 2012.

[26] J.-Q. Huang, B. Li, and W. Chen, "A CMOS MEMS humidity sensor enhanced by a capacitive coupling structure," Micromachines, vol. 7, p. 74, 2016.

[27] A. Bodini, M. Serpelloni, E. Sardini, N. Latronico, M. R. Tommasi, and M. Filippini, "Low-power wireless system for temperature and humidity monitoring in artificial ventilation," in Proceedings of the 11th IEEE International Symposium on Medical Measurements and Applications, MeMeA 2016, Italy, May 2016.

[28] Honeywell, "HIH-3610 Humidity Sensor".

[29] N. Wildmann, F. Kaufmann, and J. Bange, "An inversemodelling approach for frequency response correction of capacitive humidity sensors in ABL research with small remotely piloted aircraft (RPA)," Atmospheric Measurement Techniques, vol. 7, no. 9, pp. 3059-3069, 2014.

[30] J. J. Steele, G. A. Fitzpatrick, and M. J. Brett, "Capacitive humidity sensors with high sensitivity and subsecond response times," IEEE Sensors Journal, vol. 7, no. 6, pp. 955-956, 2007. 


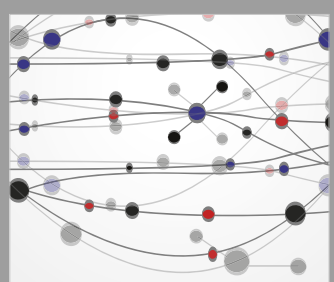

The Scientific World Journal
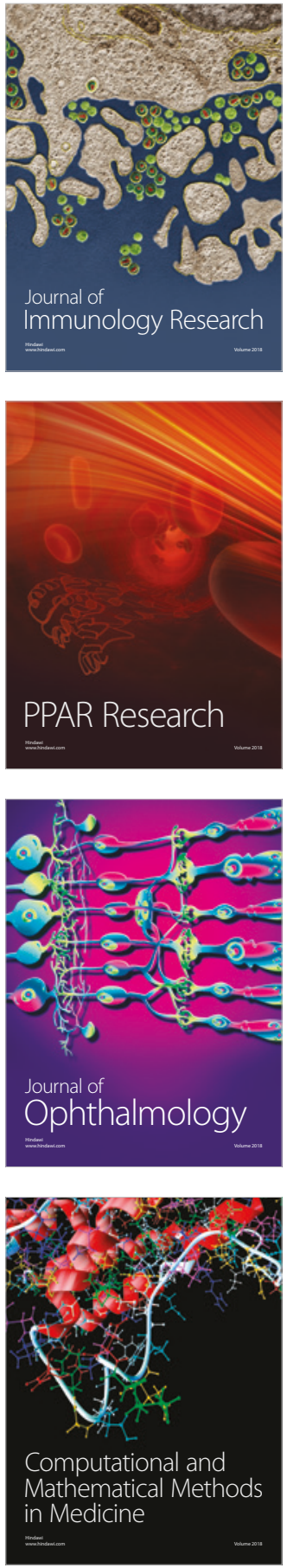

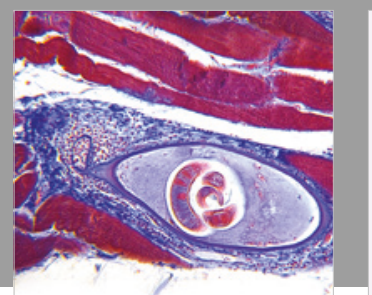

Gastroenterology Research and Practice

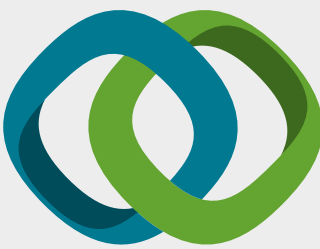

\section{Hindawi}

Submit your manuscripts at

www.hindawi.com
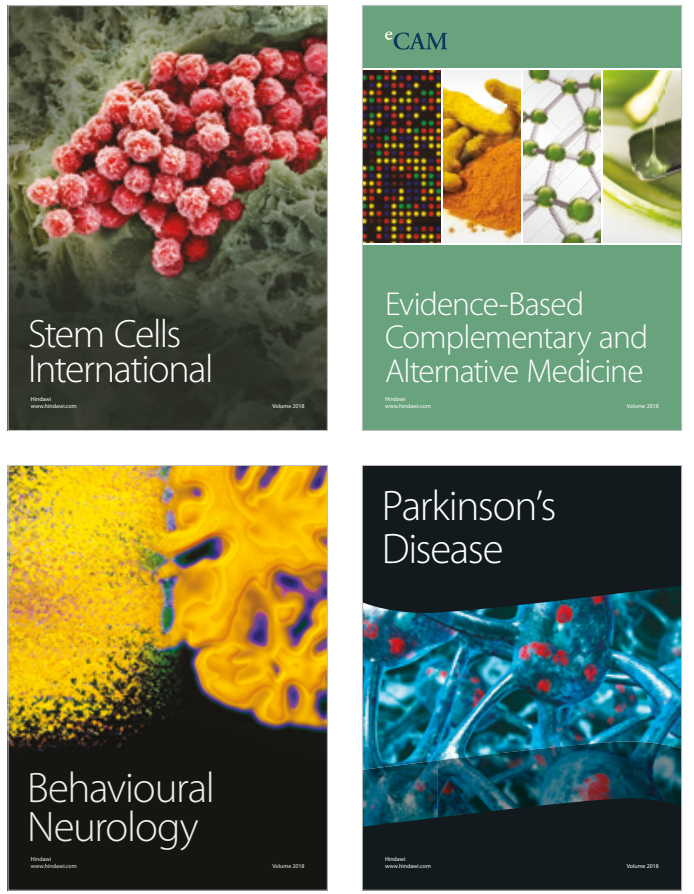

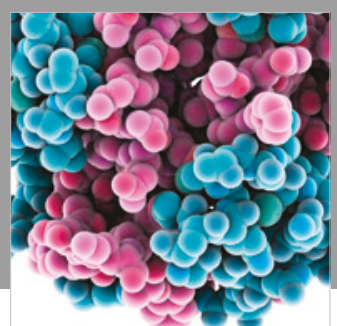

ournal of

Diabetes Research

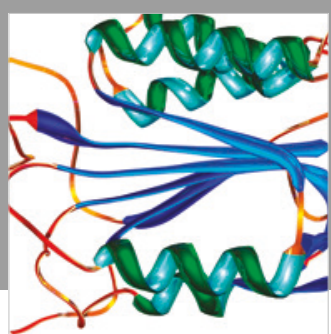

Disease Markers
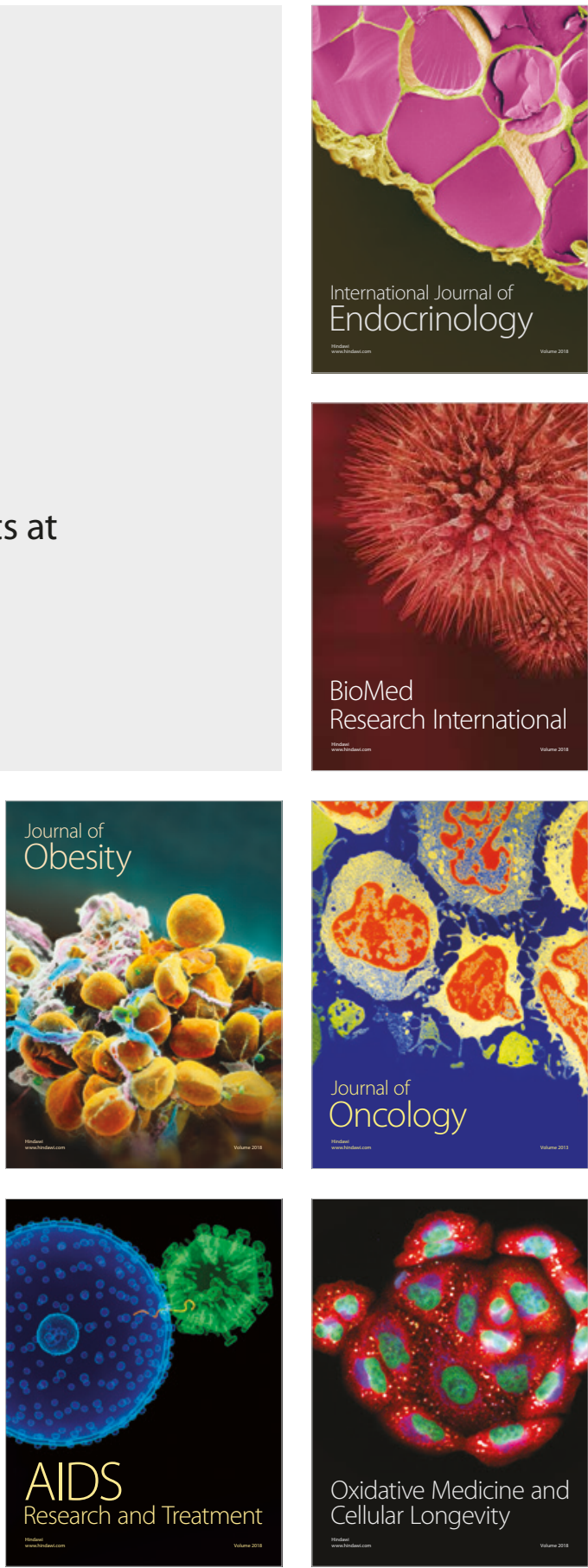